\title{
O crescer bilíngue de Codas: memórias da infância na passagem pela escola
}

\author{
Codas' bilingual growth: childhood memories in school
}

El crecimiento bilingüe de Codas: recuerdos de la infancia durante la escuela

\author{
Ricardo Ernani Sander \\ Professor doutor da Universidade Tecnológica Federal do Paraná, Campo Mourão, PR, Brasil \\ E-mail: ricsander@gmail.com ORCID: https://orcid.org/0000-0002-6004-7615
}

Sandra Eli Sartoreto Martins

Professora pós-doutora da Universidade Estadual Paulista Júlio de Mesquita Filho, Marília, SP, Brasil

E-mail: sandra.sartoreto@gmail.com ORCID: https://orcid.org/0000-0002-4247-1447

Recebido em 12 de setembro de 2021

Aprovado em 06 de dezembro de 2021

Publicado em 27 de dezembro de 2021

\section{RESUMO}

O artigo tem como objetivo identificar as marcas identitárias de filhos ouvintes de pais surdos - Codas, como sujeitos bilíngues e biculturais, que se estabelecem na escola. Tratase de um recorte dos enunciados produzidos em uma pesquisa de doutorado na área da Educação, no encontro do pesquisador com quatro Codas, de diferentes estados brasileiros. O método empregado na produção dos dados se ancora na concepção da metodologia biográfico-narrativa, sendo sua análise e discussão organizadas em núcleos de significação. A investigação evidenciou marcas identitárias que constituem a singularidade dos sujeitos pesquisados. À luz dos estudos bakhtinianos a materialidade da apreensão do objeto de análise perfila sobre a formação do ser Codas pela alteridade, na fronteira de duas línguas e culturas de prestígio social diferentes, em suas memórias da/na escola. Todavia os contornos identitários circunscrevem enunciados de um "mundo precoce adulto" que incide sobre a infância, fora dos muros escolares. Tais aspectos convocam os profissionais da educação a refletirem sentidos outros, no tempo e espaço das experiências dos que se reconhecerem ou não ouvintes, na visualidade da língua de sinais com seus pais surdos.

Palavras-chave: Codas; Identidade; Escola.

\section{ABSTRACT}

The article aims to identify the identity marks of hearing children of deaf parents - Codas, as bilingual and bicultural subjects, who settle in school. This is an excerpt of the statements produced from a doctoral research in the area of Education, in the researcher's meeting with four Codas, from different Brazilian states. The method used in the production of data is anchored in the conception of the biographical-narrative methodology, with its analysis and discussion being organized into meaning cores. The investigation evidenced identity marks 
that constitute the singularity of the researched subjects. In the light of Bakhtinian studies, the materiality of the apprehension of the object of analysis outlines the formation of the Codas being through alterity, on the border of two languages and cultures of different social prestige, in their memories of/in school. However, the identity contours circumscribe statements of an "early adult world" that focuses on childhood, outside the school walls. Such aspects invite education professionals to reflect on other meanings, in the time and space of the experiences of those who recognize themselves or not, in the visuality of sign language with their deaf parents.

Keywords: Codas; Identity; School.

\section{RESUMEN}

El artículo tiene como objetivo identificar las señas de identidad de los hijos oyentes de padres sordos - Codas, como sujetos bilingües y biculturales, que se establecen en la escuela. Este es un extracto de las declaraciones producidas en una investigación de doctorado en el área de Educación, en el encuentro de investigadores con cuatro Codas, de diferentes estados brasileños. El método utilizado en la producción de datos está anclado en la concepción de la metodología biográfico-narrativa, siendo su análisis y discusión organizados en núcleos de significado. La investigación evidenció marcas de identidad que constituyen la singularidad de los sujetos investigados. A la luz de los estudios bakhtinianos, la materialidad de la aprehensión del objeto de análisis perfila la formación del ser Codas a través de la alteridad, en la frontera de dos lenguas y culturas de diferente prestigio social, en sus memorias de / en la escuela. Sin embargo, los contornos de identidad circunscriben las declaraciones de un "mundo de la edad adulta temprana" que se centra en la infancia, fuera de los muros de la escuela. Dichos aspectos invitan a los profesionales de la educación a reflexionar sobre otros significados, en el tiempo y espacio de las vivencias de quienes se reconocen o no, en la visualidad de la lengua de signos con sus padres sordos.

Palabras clave: Codas; Identidad; Colegio.

\section{Introdução}

Neste artigo trazemos reflexões a respeito dos filhos ouvintes de pais surdos, chamados de Codas $^{1}$, cuja sigla se dá a partir de um acrônimo da língua inglesa. Os Codas se constituem linguisticamente primeiro como usuários da língua de sinais, que no caso é a Língua Brasileira de Sinais - Libras, visto que os pais são usuários da língua visual. Ao chegarem à escola se dão conta de que são diferentes dos demais alunos, por diversas questões e situações que os constituem usuários de uma outra língua e cultura, que não é conhecida e nem usada em sua casa. Os Codas crescem bilíngues, no caso usam a Libras e língua portuguesa, e são bimodais devido as duas línguas em questão 
http://dx.doi.org/10.5902/1984686X67637

serem de modalidades diferentes, isto é, enquanto a Libras é pela via visual-espacial, a língua portuguesa é pela via oral-auditiva.

Pesquisadores do campo dos Estudos Surdos em Educação e Estudos Culturais defendem a importância da apropriação da língua de sinais desde a tenra idade (SKLIAR, 1998; SILVA, 2014). Neste sentido os Codas apresentam o desenvolvimento do pensamento mediado pela língua de sinais - que é completa e complexa, sendo possível acessar as funções superiores do pensamento, utilizando-se outras vias, que não a oral auditiva, e sim a visual gestual (VIGOTSKI, 2001).

As línguas diferentes impactam significativamente na constituição dos Codas, enquanto adquirem as duas línguas, em espaços diferentes - casa e escola. A partir da entrada na escola é que se dão conta que são diferentes da maioria dos seus colegas, dos pais dos amigos e da forma de comunicação dos demais. É na escola que percebem que os seus professores não sabem se comunicar com seus pais, que os eventos escolares são pensados para os pais ouvintes e não para os pais surdos. Na escola descobrem assombrados que a sociedade desconsidera possibilidades da presença de seus pais surdos nos espaços e atividades acadêmicas e administrativas por ela organizadas.

Seguindo até sua vida adulta os Codas se constituem revelando marcas identitárias sociais e de vivências únicas em sua existência. Marcas estas que tornam visíveis aspectos da sua subjetividade identitária como sujeitos não surdos que crescem em meio ao "mundo" do(s) surdo(s). Estas se caracterizam linguística e culturalmente em fronteiras, cujos espaços exclusivos pertencem somente a eles. Não há entre a sociedade humana peculiaridade igual a dos Codas, a quem objetivamos dar destaque neste texto.

A partir do recorte de uma pesquisa mais ampla de doutorado ${ }^{2}$, cujos sujeitos Codas são vistos como coautores da investigação, os quatro participantes - Nina, Kauê, Kayke e Guaracy, se circunscrevem com modos e vivências das suas experiências de vida localizadas em quatro estados brasileiros diferentes. Atuando em universidades públicas, dois deles são professores e dois tradutores intérpretes de Libras, todos com formação em programas de Pós-graduação, sendo dois em nível de mestrado e dois de doutorado.

Em vista disso, o artigo tem como objetivo identificar as marcas identitárias de filhos ouvintes de pais surdos - Codas, como sujeitos bilíngues e biculturais desde a escola. 
http://dx.doi.org/10.5902/1984686X67637

\section{Metodologia: o caminho percorrido na produção dos dados de pesquisa}

À luz dos estudos culturais de Silva (2014), Skliar (1998), Woodward (2000) aliados aos aportes de Bauman (2011), Hall (2011), Preston (1994), Quadros (2007, 2017), Souza (2014), autores e teóricos do Círculo de Bakhtin ${ }^{3}$, recorreremos à compreensão da subjetividade humana na constituição identitária do ser Coda, como processo único, inacabado e em contínua transformação.

A pesquisa qualitativa a que se refere este artigo é um recorte da investigação de doutorado (Sander 2020), que coletou os dados por meio de entrevistas recorrentes gravadas em vídeo e transcritas para a língua portuguesa, cujas narrativas trazem parte das histórias de vida de cada um dos quatro Codas entrevistados. A coleta seguiu de acordo com a metodologia de Moriña (2017) intitulada de biográfico-narrativa. A organização e a análise dos dados foram ancoradas a partir das orientações de Aguiar e Ozella (2006, 2013), denominada de núcleos de significação - NDS.

Os sujeitos da pesquisa foram selecionados a partir da lista de endereços de e-mails do pesquisador, cujos convites foram disparados para treze contatos. Retornaram quatro respostas afirmativas em que os Codas se colocaram à disposição para participarem da investigação. Os participantes são Codas de diferentes estados brasileiros, todos atuantes e militantes nos movimentos surdos e de tradutores intérpretes de língua de sinais.

Os contatos iniciais foram por e-mail, depois através do WhatsApp. Houve três encontros pelo Skype com cada um deles, cujas entrevistas foram gravadas pelo programa Callnote e salvas no Google Drive. As perguntas foram enviadas previamente por e-mail, os encontros agendados e as questões abordadas conforme fluíam as falas. Não se seguiu a rigor as questões planejadas para os encontros. As entrevistas foram feitas em língua portuguesa oral, transcritas e organizadas para as análises.

Cada um dos quatro participantes desta investigação recebeu um codinome indígena (Nina, Kauê, Kayke e Guaracy) em homenagem aos grupos indígenas brasileiros, cujas línguas também são de minorias, como a Libras. As entrevistas iniciaram apenas após o aceite dos participantes e o recebimento assinado do Termo de Consentimento Livre e Esclarecido (TCLE), devidamente autorizado na Plataforma Brasil. ${ }^{4}$

Os dados transcritos renderam abundantes informações, as quais foram agrupadas em cinco núcleos de significação, que se constituem nos seguintes: 1) As narrativas que marcam a maturidade precoce na constituição da subjetividade dos Codas; 2) A formação dos Codas como sujeitos bilíngues e biculturais; 3) O orgulho dos pais como cidadãos de 
http://dx.doi.org/10.5902/1984686X67637

direito em sociedade; 4) Os aspectos do processo formativo escolar e universitário; 5) Codas: os primeiros tradutores e intérpretes nas relações dos pais surdos em sociedade.

A investigação pretendeu trazer aos olhares da sociedade as marcas identitárias dos Codas que se tornam visíveis a partir de aspectos na constituição da subjetividade da identidade em espaços de vivências afetivas, como na família e de maneira especial na escola.

$\mathrm{Na}$ sequência apresentaremos os pressupostos teóricos e metodológicos que fundamentam este artigo, como as marcas da subjetividade identitária dos coautores deste estudo e posterior, as considerações finais.

\section{Constituição subjetiva e identitária do Ser Coda}

Minha imagem de mim mesmo. Qual a índole da concepção de mim mesmo, do meu eu em seu todo? Em que ele se distingue essencialmente da minha concepção do outro? [...] Eu-para-mim e eu-para-o-outro, o outro-para-mim. $\mathrm{O}$ que em mim dado imediatamente e o que dado apenas através do outro (BAKHTIN, 2011, p. 382).

Assumir a compreensão da subjetividade da constituição identitária do Ser Coda 5 implica reconhecer que todos somos constituídos desde o início da existência, e que as nossas relações subjetivas de formação identitária se estabelecem continuamente ao longo da vida, inacabadas e ativas, sendo essenciais para o sujeito enquanto ser consciente e pensante. Elas se estabelecem a partir da linguagem, posteriormente da língua e da cultura. A linguagem é um universo de elementos abstratos daquilo que imaginamos ou não, de infinitas possibilidades para a compreensão, expressão, interação e encontros dialógicos da existência humana.

Defender a compreensão da subjetividade nas relações em que o sujeito se reconhece e/ou assume Coda, está ancorada em uma perspectiva de formação identitária que tem origem e essência na cultura humana.

Sendo assim, identidade é definida segundo Hall (2014)

[...] o ponto de encontro, o ponto de sutura entre, por um lado, os discursos e as práticas que tentam nos 'interpelar', nos falar ou nos convocar para que assumamos nossos lugares como os sujeitos sociais de discursos particulares e, por outro lado, os processos que produzem subjetividades que nos constroem como sujeitos aos quais se pode 'falar' (HALL, 2014, p. 111112).

O teórico da filosofia, o polonês Zygmunt Bauman, citado por Regis (2015) define identidade como 
http://dx.doi.org/10.5902/1984686X67637

[...] pelo pertencimento de um indivíduo a uma dada comunidade, sob a condição deste indivíduo dotar de características específicas prescritas pela comunidade, dentre as quais hábitos, comportamentos, valores, sentimentos, ações, ideias, preferências, ascendência, fenótipos. (REGIS, 2015, p. 290295).

Aliados a tais ponderações Bakhtin (2010) nos interpela a esse respeito ao afirmar que somos constituídos pelo outro e que sujeito é social na relação com o outro. A compreensão que o eu e o outro se relacionam dialogicamente e, assim, se constituem enquanto seres humanos. Nossa humanidade não se constitui sozinha, mas sempre em relação ao outro. Nos construímos, nos fazemos com o outro, pelo outro e no outro, continuamente. O outro existe e se constitui em mim, através de mim e com minha existência. É um ir e vir entre os seres humanos, sem nunca ter fim. É a dialogia que nos constitui continuamente, enquanto sujeitos humanos, inacabados e em mudanças ininterruptas.

Nesta teia de significados, para discorrer sobre a subjetividade identitária, acrescentase o papel que a cultura ocupa nas relações do homem com a natureza. Tomada na obra de Bakhtin/Volochínov (2014) na sua crítica ao Marxismo e Filosofia da Linguagem, que vê a origem da cultura nas mudanças e sentido das palavras, que se originam nas relações dialógicas

[...] a realidade, ou seja, (a infraestrutura) determina o signo, como o signo reflete e refrata a realidade em transforma o [...]. As palavras são tecidas a partir de uma multidão de fios ideológicos e servem de trama a todas as relações sociais em todos os domínios. É, portanto, claro que a palavra ser sempre o indicador mais sensível de todas as transformações sociais. (BAKHTIN/VOLOCHÍNOV, 2014, p. 42).

A transformação constante na sociedade é causada pelas mudanças dos signos, isto é, dos significados que se criam entre os indivíduos, usados no seu dia a dia, no seu trabalho constante de transformação da natureza, no meio social. A origem da cultura, e como ela é produzida, tem suas raízes na existência do próprio homem, que usa sua capacidade intelectual e interage com a natureza, que é modificada com as forças dele próprio. A interação acontece por meio do trabalho, que modifica não somente a natureza sobre a qual o homem age, mas também a ele próprio. 
http://dx.doi.org/10.5902/1984686X67637

\section{Viver na fronteira da "zona de contato" da constituição da subjetividade identitária por transitar em dois mundos(s) diferentes: do(s) surdo(s) e não surdo(s)}

Pratt (2000), pesquisadora na área da linguagem e literatura de línguas modernas, da Universidade de Nova lorque, é autora da expressão "zona de contato", empregada pela primeira vez em 1991 quando discursou na Academia de Línguas Modernas, da sua universidade. É atualmente uma teoria bastante citada na área da linguística, estudos culturais e transculturais (SILVA 2014; SKLIAR 1998). Quando se refere "zona de contato", a autora afirma que as línguas - duas ou mais, se encontram. Nesse espaço há competição de poder entre as línguas que se encontram. Os encontros dizem respeito a espaços sociais e culturais. A autora pontua que quando as pessoas migram de um país para outro, deixam os seus pertences nos seus locais de origem. Não carregam muito do que era seu, porém a língua vem junto. A língua faz necessariamente parte da bagagem. As línguas viajam com seus donos. Este fenômeno é muito evidente atualmente com a globalização, a migração de refugiados e imigrantes entre os mais diversos países. É desta forma que ocorrem os embates sociais e culturais. São as disputas de poder entre as línguas.

As línguas se mantem vivas e se movimentam mundo afora recebendo influências do tempo, do espaço e das diferenças culturais dos povos que se encontram. Nestes espaços se confrontam, caracterizando as fronteiras. Dito de outro modo, os Codas, constantemente, vivem em zonas de fronteiras da Libras e da língua portuguesa e, crescem bilíngues e biculturais, sendo atravessados por experiências singulares nas relações vividas com os membros da família, nos espaços de convivência social e na escola. Uma vez que entendemos que os Codas estão na fronteira entre duas línguas, e sempre crescerão numa condição bilíngue e bicultural, porém significa se perceber pertencente a um grupo que "fala somente com a boca", segundo um dos Codas entrevistados. Essa biculturalidade é conscientemente percebida numa idade mais madura, quando em contato com outros usuários da língua portuguesa, na escola.

Outrossim, os Codas aprendem que são diferentes dos seus pais, na relação com o outro, fora de casa, espaço de convivência muito diferente do que até então tiveram oportunidade de conhecer para além do contexto familiar. No encontro com o outro se reconhecem como sujeitos bilíngues e biculturais. 
http://dx.doi.org/10.5902/1984686X67637

\section{O que dizem os Codas sobre o crescer bilíngue e bicultural}

\section{A maturidade precoce}

Ser ponte para a sociedade ouvinte e seus pais surdos e vice-versa é uma atribuição recorrente para o Coda. Esta função ocorre, em geral, naturalmente e, por conseguinte, por necessidade dos pais surdos que, em geral, usam a língua de sinais em casa, entre si, em família com seus filhos. Porém, quando se faz necessário entender e se comunicar com as pessoas não surdas, os Codas são requisitados pelos próprios pais para assumir esta função.

Segundo Camparoto (2020) Coda, desabafa em sua página de rede social

- Só a gente sabe o que foi deixar de brincar na rua para ajudar os pais surdos. Só a gente sabe o quanto choramos ao ouvir palavras toscas e todo o preconceito da sociedade por sermos uma família diferente do padrão. Só a gente sabe o quanto lutamos, juntas, para conquistar a acessibilidade aos nossos pais. Só a gente sabe o quanto a vida nos cobrou, deixamos de ter uma infância para viver como adultas em consultas e dicas, filas de banco, palestras, reuniões escolares etc. E... as circunstâncias nos fizeram mulheres quando ainda meninas. ${ }^{6}$

A autora resgata memórias de tempos da sua vida na infância, em um período em que os pais demandavam coisas diferentes das demais famílias. Em geral, cabiam aos Codas terem que se ocupar da mediação da comunicação nos momentos de apresentação dos telejornais, programas de TV, nas visitas em bancos, lojas, consultas médicas e tantos outros eventos de comunicação.

Silva (2018) ao se referir sobre o assunto dos filhos ouvintes de pais surdos, acrescenta momentos em que constantemente participava das conversas, assuntos mobilizados pelos adultos que frequentemente se sentiam obrigados a emprestarem seus ouvidos aos seus pais surdos, que por vezes os responsabilizavam por decisões e/ou atribuições sem que pudessem compreender os assuntos dos quais partilhavam.

Na investigação de Sander (2020, p. 237), um dos entrevistados, Kaíke, relata outrora, que era constrangido a interpretar temas "[...] íntimos e sensíveis para os surdos, além de meus pais".

Situações constrangedoras para os Codas, também trazidas por Burge (2018, p. 33) em seu relato sobre a vida de Emily - uma das suas entrevistadas, menciona: "Quando eu era criança, ouvia pessoas xingando e eu traduzia para minha mãe os xingamentos das pessoas, e daí, as pessoas me amaldiçoavam porque traduzia." 
http://dx.doi.org/10.5902/1984686X67637

Essas e muitas outras situações e questões que estão além da maturidade emocional, psíquica e biológica dos filhos de pais surdos são trazidos em pesquisas, cujas condições os forçaram a se tornarem maduros e adultos antes do tempo.

\title{
Uma formação bilíngue e bicultural
}

Neste tópico abordaremos sobre a formação dos Codas enquanto cidadãos bilíngues e biculturais

\begin{abstract}
A herança bilíngue e bicultural dos filhos ouvintes de pais surdos, fornece uma fonte única de análise e de compreensão do leque de experiências humanas, na medida em que Preston (1994) enquanto Coda, afirmar que somos iguais e somos diferentes. E, como aprendemos com nossos pais e nossas famílias, as diferenças devem a ser reconhecidas, valorizadas e comemoradas (PRESTON, 2008, p. 9).
\end{abstract}

Na mesma direção a Coda Nina, entrevistada por Sander (2020, p. 115), acrescenta a esse respeito:

\begin{abstract}
- Minha mãe abria os livros diante de nós três irmãos, e ela contava as histórias. Meu pai não contava histórias, mas minha mãe contava histórias. Ela lia as gravuras e a partir daí contava as histórias. Ela era analfabeta no Português. Ela mostrava um passarinho e sinalizava:
\end{abstract}

- Olha o passarinho. Que lindo. Que cores lindas nas penas.

Assim, não prestava atenção nos cantos dos passarinhos, mas nas expressões visuais, formas, cores. Outro dia vovó me perguntou:

- Você viu que o passarinho canta?

- Não, não vi que ele cantava.

- Para mim ele grita e não canta. Cantar era outra coisa, pra mim. Nestes e noutros aspectos eu vejo que Coda diferente. A gente é diferente.

O episódio acima evidencia uma narrativa na qual as experiências com a oralidade e percepções sonoras eram diferentes das de uma criança filha de pais ouvintes. Quando a entrevistada descreve que pensava que o passarinho gritava, mas não cantava, certamente era o que percebia. $\mathrm{O}$ ouvido dela não foi treinado para que o grito do passarinho fosse significado como um canto melodioso. Ela ouvia o passarinho, mas seus pais não. Eles não diziam 'escuta o canto do passarinho como é lindo', porque essa é uma experiência de quem ouve. O som, certamente, não estava na lista de prioridades dos pais da Coda, até porque a língua que usavam não tem as mesmas características de uma língua oral.

A percepção do canto para surdos é diferente daquela dos não surdos ${ }^{7}$. As concepções dos pais surdos sobre o passarinho são fundamentadas nas características 
http://dx.doi.org/10.5902/1984686X67637

visuais, nos diferentes inputs que recebem visualmente, que são repassadas e ensinadas aos filhos. Para os filhos ouvintes de pais ouvintes, o ponto de vista do aprendizado vem por outro viés, o auditivo.

Os pais não surdos percebem os sons do que chamam de canto do passarinho. Eles chamam a atenção a respeito do canto e o ensinam para seus filhos, dando significado. Eis um ponto de vista diferente, não inferior ao outro. Uma concepção visual e outra concepção auditiva. Ambas, porém, vêm com informações garantidas e importantes, que constituem uma perspectiva, uma visão outra sobre o passarinho, que não a auditiva. É um exemplo potente da linguagem dando sentido às experiências, ou seja, os processos de significação, em que a avó ouvinte deu a entender o som produzido pelo passarinho, que para a Coda não tinha o mesmo significado. Neste sentido, vemos aqui a proximidade da cultura surda com a dos Codas. Essa proximidade entre ambas é devido a mesma língua e visão que constroem sobre as coisas do/no mundo. Diferentemente, para o mundo do não surdo, a visão das coisas e suas concepções estão baseadas na audição e na visão.

Para Pratt (2000), a ideia dos dois mundos é assertiva, pontuando que o universo surdo e não surdo marca as fronteiras dos Codas, o qual define zonas de contato como aqueles espaços sociais em que as culturas se encontram e se constroem em linhas de diferenças, em contextos assimétricos de poder.

Respaldando essa concepção, Quadros e Massutti (2007, p. 248) afirmam

São nas convivências, no cenário cotidiano, que os sentidos e as operações tradutórias vão sendo exigidas dos sujeitos envolvidos nas relações de grupo, desafiando linguagens e articulando a língua dentro dos laços culturais. Os CODAs, desde a sua tenra idade, aprendem que nem sempre o princípio de equivalência linguística é possível, trata-se de mundos diferentes e que tornam abissais as diferenças.

O próprio crescimento bilíngue, e, portanto, bicultural, é um amadurecimento precoce forjado verdadeira e genuinamente na casa dos Codas, mas que também trazem outras marcas, como veremos na continuidade.

\section{Orgulho em ser Coda}

Uma das bases da nossa autoestima e do empoderamento enquanto cidadão, sujeito consciente e vivo é o orgulho de si. Aqui trataremos do orgulho dos pais surdos por terem filhos não surdos e vice-versa. O orgulho é em consequência do reconhecimento de um sujeito consciente, da militância e dos movimentos das minorias, do pertencimento aos grupos da alteridade e da própria resiliência epistemológica do sujeito. 
http://dx.doi.org/10.5902/1984686X67637

Como relata a Coda estadunidense Lou Ann Walker (1987) no tempo em que começou a escrever sobre seus pais, ela aprendeu tremendamente sobre a vida, e acrescentou que encontrou muito sobre si mesma.

O pesquisador surdo britânico Paddy Ladd cunhou o termo 'deafwood' (na língua inglesa), em 1990, o qual foi traduzido e usado no português brasileiro como 'ser surdo', ou "surdidade" em Portugal. O autor objetiva trazer um significado díspar, que não uma visão clínica de deficiência e de necessidade de reabilitação, de restauração da pessoa surda usuária de uma língua visual.

Para ele, os surdos não são como as pessoas idosas que já perderam a acuidade auditiva, ou vistos como se fizessem parte do grupo dos deficientes auditivos. Porém, para o autor, os surdos se constituem a "[...] verdadeira natureza da existência coletiva de surdos que foi dada como invisível". (LADD, 2003, p. 281). A diferença é a língua visual e cultura que a comunidade surda usufrui.

Ladd (2003, p. 292) afirma

Ser surdo não é visto como um estado finito, mas como um processo pelo qual os indivíduos surdos passam a efetivar sua identidade surda, postulando que esses indivíduos constroem essa identidade em torno de vários conjuntos de prioridades e princípios ordenados de forma diferente, que são afetados por vários fatores, como nação, época e classe.

Os pesquisados Codas aprendem a ter orgulho pelas duas línguas que sabem e falam, bem como as visões que os constituem, em parte da comunidade surda e em parte da sociedade ouvinte, na qual demonstram estar a altivez e o sentimento de orgulho dos seus pais surdos, conforme Sander (2020, p. 125) na descrição da narrativa de Nina a seguir:

- No primeiro dia minha mãe me levando para a escola, eu senti que as pessoas me olhavam [...] então, perguntei à mamãe:

- Por que estão olhando para mim?

Mamãe olhou pra mim e disse, com expressão de orgulho, porque ela sabia da questão de ser surda e dos olhares.

Sinalizando disse:

- Porque você sabe duas: sinais e fala.

Nós duas nos entreolhamos e havia muito orgulho e satisfação na resposta da mamãe.

- Verdade, respondi. 
http://dx.doi.org/10.5902/1984686X67637

- Daí eu me senti. Ela queria mostrar isso pra mim. Me senti empoderada. Me senti forte. Porque a minha mãe me fez forte. Naquele momento foi importante ela me dizer isso:

- Você sabe duas línguas, eles não sabem. Minha mãe me fez forte!

Mamãe sinalizou:

- Eles não sabem. Eles não sabem.

$\mathrm{Na}$ passagem apresentada, os pais surdos enfrentaram os estigmas com altivez, na medida em que buscaram auxiliar a filha no enfrentamento dos olhares curiosos dos colegas da escola, sobre a língua de sinais. A mãe surda, imediatamente tomada pelo estranhamento e pelos olhares de estigma, tece palavras encorajadoras à filha, de valorização pela sua condição bilíngue frente às atitudes hostis do mundo, diante dos estereótipos e preconceitos atribuídos a comunidade surda e seu entorno. A mãe já tinha conhecimento a respeito, porém, a filha, não. Nessa narrativa a mãe procura proteger a criança, destacando valores positivos da língua de herança e da relação de cumplicidade entre elas. É a língua de sinais que as une na experiência afetiva e de conforto identitário linguístico. Ambas são usuárias da Libras e é aí que são vistas como diferentes e cúmplices do mesmo estigma.

Em um de seus textos, Faraco (2009, p. 55) relata sua visão a respeito da concepção de Bakhtin, "[...] o simples fato de eu ter começado a falar sobre ele já significa que assumi certa atitude em relação a ele". Os pais falam dos filhos e os filhos dos pais, com orgulho, numa troca dialógica com elo afetivo e de cumplicidade. É um ato responsável na concepção de Bakhtin.

\section{Da escola à universidade}

A visão dos pais em relação aos filhos vai além do momento na infância, inclui o futuro. Como pontua Amorim (2001, p. 289) "A distinção entre horizonte e ambiente confere aos olhares uma dissimetria constitutiva nomeada por Bakhtin como um surplus da visão do outro sobre mim". Os pais surdos tiveram uma visão excedente, ou seja, além sobre seus filhos não surdos e suas famílias. Todos os quatro sujeitos da pesquisa relataram que os pais queriam que eles estudassem, entrassem na universidade e tivessem boa formação e carreira profissional.

De acordo com Rodriguero e Yaegashi (2013), a família é o primeiro núcleo das interações do indivíduo. É na família que se iniciam muitos sonhos, um deles diz respeito à 
http://dx.doi.org/10.5902/1984686X67637

formação, cursos e universidade. Os pais são os grandes incentivadores e responsáveis pela educação inicial de seus filhos.

O trajeto desde o início da escola básica até a graduação na universidade é bastante longo, ocupando boa parte da vida do sujeito. Muitos percalços são trazidos pelos entrevistados em suas narrativas, porém, apresentamos apenas alguns.

O primeiro dia na escola de um dos sujeitos entrevistados, revelam aspectos de angústia e sofrimento, conforme relata o Coda Nina entrevistada por Sander (2020, p. 131)

- São apenas pessoas, e Deus é muito bom pra gente, mas a escola mostrou pra mim, quem eram meus pais. $E$ foi doloroso a forma com que a escola mostrou. As pessoas me olhavam. Mas a escola para mim foi massacrante. Foi para mim e para meus irmãos. Daí começaram as reuniões de pais. Mamãe foi com a minha vó uma vez, minha mãe não entendeu nada. Daí a própria escola falou, a professora falou que meu papai e minha mamãe não precisariam vir mais nas reuniões, porque difícil. Não entendi por que era muito difícil? Eu levava as questões para meus pais, mas não sabia do que se tratava.

Mamãe disse:

- A escola é burra. A escola não sabe conversar com a gente.

- A partir daquele momento nunca mais meus pais foram. De vez em quando a minha vó ia.

Nesta narrativa observa-se uma profunda decepção da entrevistada Coda ao chegar à escola, no primeiro dia de aula. O desencanto é reafirmado no discurso pela percepção da Coda em relação aos sentimentos que demonstraram seus pais sobre o episódio narrado.

Esta percepção é retomada no trecho do relato de outro entrevistado no estudo de Sander (2020, p. 133). Desabafa o Coda Guaracy

- Mas lembro de quando íamos na escola. E na escola tinha reunião de pais
e mestres. Nestas reuniões havia agendamento de eventos e outras próximas
reuniões. A escola, às vezes, mudava a data da reunião em cima da hora e
eu avisava minha mãe sobre a reunião. Depois, que a reunião foi postergada
pela escola e minha mãe falava assim:

- Como assim, a reunião não estava marcada? Esta escola é muito enrolada. Desmarca hoje para amanhã. Isto não pode acontecer. Ela não conseguia entender muito bem isso.

Nestas passagens observam-se omissão da escola de garantias de acesso e participação dos pais surdos nas reuniões de pais e mestres. Por sua vez, a escola parece 
http://dx.doi.org/10.5902/1984686X67637

postergar e/ou negar que pudessem acompanhar a vida acadêmica de seus filhos, mantendo-os na situação da invisibilidade.

Em outra transcrição semelhante ao contexto mencionado, trazida no estudo de Sander (2020, p. 133) que se refere aos momentos de acompanhamento dos pais nas atividades de estudo em casa, feita pelo Coda Kauê, nesta narrativa

- Hoje eu sei por que estava com meus pais surdos. Eles não tiveram oportunidade de estudar. Mas sempre me falavam:

- Importante você estudar; não deixa de estudar.

- Quando estudava, eles não me chamavam, eles não interrompiam para que eu pudesse estudar. Era um dos poucos momentos, mas não me chamavam. Hoje eles me contam que observavam de longe, e me deixavam quieto.

- Depois, quando terminava eu era solicitado a intermediar, interpretar pra eles. Claro, havia exceções, mas no geral eles me deixavam estudar.

- Era diferente dos meus colegas que pediam ajuda para seus pais, com explicações de tarefas, acompanhavam alguma coisa, tirava alguma dúvida. Eu era sozinho e tinha que me virar nos estudos.

No exemplo do relato do Coda nota-se que contava pouco com auxílio dos pais nas atividades extraclasses, o que exigia um grau maior de autonomia, maturidade, concentração nas formas de organização da rotina escolar.

$\mathrm{Na}$ fase adulta os Codas revelam informações a respeito do período que estiveram na universidade. O Coda Kaíke, em uma de suas narrativas, observou que se deu conta da questão da Libras como língua, que era tão natural para ele, somente quando estudava no Ensino Médio, conforme traz o estudo de Sander (2020, p. 138)

- No terceiro ano do Ensino Médio, quando fui lendo alguns textos sobre isso,
teve uma palestra no mês de setembro, inclusive, sobre o dia do surdo, e tudo
aquilo, o setembro azul, aí acabou uma pessoa surda dando essa palestra.
Tinha um intérprete da surda e eu me via muito ali, interpretando no lugar do
intérprete. Foi no auditório da escola. A partir daí, tive essa consciência de
que são duas línguas realmente, e fui me encarando nesta perspectiva
bilíngue. E na universidade, me consolidei meu pensamento enquanto
consciência, enquanto conscientização, enquanto categoria, enquanto ser
bilíngue.

Em outra narrativa na investigação sobre Codas, Sander (2020, p. 132) revela situações vividas por Nina durante a sua formatura de faculdade, momento considerado por ela como marcante na história da família. 
http://dx.doi.org/10.5902/1984686X67637

- Na hora da homenagem aos pais, eu pedi para interpretar esta parte da formatura. Tinha intérprete presente, mas eu queria interpretar aquela parte. Não estava no cerimonial a minha atuação como intérprete. Mas eu queria fazer isso para meus pais surdos que estavam lá. Aí perguntei:

- Eu posso interpretar a homenagem? Me permitiram e eu subi no palco. Aí, na hora da homenagem aos pais, eu não interpretei as palavras da homenagem, mas conversei em paralelo com meus pais. Eu falei pra eles o que queria falar. Fiz a minha homenagem pros dois. Nós três choramos.

Não lembro de outros detalhes, mas desta frase ainda me lembro, e eu disse:

- Eu não fui nada daquilo que vocês sonharam que fosse.

\section{Os primeiros intérpretes na família: eles, os Codas}

A história da tradução e interpretação da língua de sinais se dá, inicialmente, com intérpretes voluntários, sem formação acadêmica na área, especialmente nos espaços religiosos e com uma visão assistencialista. Contudo, são os Codas que aparecem como os primeiros intérpretes da língua de sinais para seus pais, no seio da família, na igreja que frequentavam e onde houvesse necessidade. Eles começaram a interpretar desde a mais tenra idade, mesmo que discretamente em suas famílias ou em qualquer outro lugar público, porque eles já usavam a língua de sinais com seus pais. Quando envolvia a comunicação com algum sujeito não surdo, os Codas entravam em cena, intermediando para seus pais e para as pessoas ouvintes. Essa atuação acontecia naturalmente, mesmo que ninguém se desse conta à época, que isso era atuação de tradução e interpretação.

Seguem afirmativas da seguinte natureza: "Os outros podiam brincar lá fora, mas eu tinha que ficar ali com meus pais, interpretando as conversas chatas" (SANDER, 2020, p. 139). Foi assim que uma das respostas é iniciada, quando perguntado se mediava a comunicação com seus pais nas atividades da comunicação com os diferentes deles - os não surdos.

A mesma questão é respondida por Kaíke, que mediava a comunicação para seus pais durante a sua infância, destacados por Sander (2020, p.144)

- Sim, muitas vezes. Não só para meus pais, mas para os amigos surdos também. Era muito engraçado, pois, eu morava no ponto final de ônibus, no bairro, eu morava num prédio. Entre o ponto de ônibus e o prédio havia uma subida. Eu jogava bola em frente ao prédio. Quando o ônibus chegava e descia um surdo, eu me escondia, pois, sabia que ele me pegava pra interpretar. Eu conhecia os surdos. Daí eu me escondia. Porque eu perdia muita coisa. Queria brincar. Eu tinha muitas coisas, tarefas, ocupações com meus pais, escola, e com os demais surdos.

- Para mim era tudo muito natural. Mas hoje quando olho eu digo: 'Caramba', era tudo muito louco. 
http://dx.doi.org/10.5902/1984686X67637

O mesmo Coda entrevistado continua sua narrativa, pois, a questão provocara nele uma resposta detalhada, segundo Sander (2020, p. 144)

\footnotetext{
- Interpretava o jornal. Muito jornal. Minha mãe sempre foi de associação (de surdos), ela sempre gostava de direitos. E jornal impresso também. Apesar do Português pra ela ter muita limitação, mas ela olhava a imagem e algumas palavras e ela queria entender. Isso exigiu muito de mim também.

- Interpretava na Pastoral da Igreja Católica. [...] Delegacias, julgamentos, reuniões de condomínio, reuniões com políticos, conselhos para pessoas com deficiência, cujas decisões iriam decidir diretamente a vida do surdo. E era interpretação sozinho por horas e horas. Interpretei um casamento quando tinha 12 anos. Vários casamentos.
}

Dessa forma, os excertos destacados ao longo do artigo nos permitem considerar que as narrativas dos entrevistados Codas, por excelência e em razão da sua trajetória de vida, acabam exercendo de forma natural as mediações para seus pais, acompanhando-os em diferentes atividades e espaços sociais. Logo, sempre se colocam dispostos e disponíveis para mediar interações deles com o mundo predominantemente ouvinte. Tais ponderações até aqui, longe de terem a pretensão da conclusibilidade, alertam para aspectos importantes da subjetividade do ser Coda, considerados fatos indispensáveis à compreensão dos que transitam nesta área dos estudos de Humanas, isto é, a escola e seus atores.

\section{Considerações finais}

O presente artigo se origina a partir de um recorte de uma tese na área da Educação, que traz relatos de filhos ouvintes de pais surdos - Codas, sobre o seu desenvolvimento linguístico, familiar e escolar. De forma mais específica, apresentamos alguns aspectos da sua subjetividade ao se reconhecerem e se revelarem sujeitos bilíngues e biculturais.

A investigação possibilitou compreender por meio das narrativas, que os Codas em geral, se sentem negligenciados pela comunidade escolar, por transitarem linguística e culturalmente em duas línguas e duas culturas, e essa condição linguística não ser identificada e reconhecida pela escola.

É na perspectiva de vida na fronteira de línguas e culturas, que as vivências diárias oportunizam muitos desafios e sucessos para ambos os lados - surdos e não surdos. Em geral, praticam a empatia para com o outro, na qual a compreensão das próprias fragilidades e de seus pais servem como inspiração para manter a resiliência na vida. 
Esta condição peculiar de assumirem logo cedo a responsabilidade tutelar da vida de seus pais, geralmente, os levam a atingir uma maturidade precoce na infância. Neste cenário a casa deixa de ser um lugar acolhedor, de diálogo e de proteção, para se tornar um local de ruptura de obstáculos e de transposição dos muros que se antepõe socialmente a si mesmos e aos seus pais. Fora do lar, vivem experiências de estigmas e exclusão, marcados por traços de uma sociedade predominantemente ouvinte. Portanto, viver e transitar nos dois mundos implica estar no território de limite entre as modalidades de cada uma das línguas - uma oral auditiva e a outra visual espacial, onde há embates e negociações entre as línguas usadas pelos Codas, em que uma tem maior prestígio do que a outra.

Os resultados da investigação nos convocam a estarmos alertas à condição, ao desenvolvimento e à proteção dos Codas na família e na escola. Quanto à escola, tem que ser um espaço acolhedor, com possibilidade de escuta e de oferta de profissionais tradutores intérpretes de Libras para mediar a comunicação da equipe da escola com os pais surdos. Outrossim, a escola deve demonstrar possibilidades de ser mais propositiva às necessidades linguísticas e educacionais dos seus alunos Codas, compreendendo a suas diferenças constitutivas identitárias, dos demais alunos.

Os coautores deste estudo - Nina, Kauê, Kaíke e Guarary, demonstraram um alto nível de formação, conhecimento e de envolvimento para dialogar sobre a temática. Ao concluirmos esse estudo, ficamos com a certeza de que as historias de vida contadas por meio dos relatos dos Codas que participaram da pesquisa serão modelos para outras gerações de Codas e suas famílias e também para as escolas que receberem Codas.

\section{Referências}

AGUIAR, Wanda Maria Junqueira de. (Org.). Sentidos e significados do professor na perspectiva sócio-histórica: relatos de pesquisa. São Paulo: Casa do Psicólogo, 2006.

AGUIAR, Wanda Maria Junqueira de; OZELLA, Sergio. Apreensão dos sentidos: aprimorando a proposta dos núcleos de significação. Revista Brasileira de Estudos Pedagógicos, Brasília, v. 94, n. 236, p. 299-322, jan./abr. 2013.

AMORIM, Marilia. O pesquisador e seu outro: Bakhtin nas Ciências Humanas. São Paulo: Musa, 2001.

BAKHTIN, Mikhail. Problemas da poética de Dostoiévski. Trad. Paulo Bezerra. 5. ed. Rio de Janeiro: Forense Universitária, 2010. 
BAKHTIN, Mikhail. Estética da criação verbal. São Paulo: Martins Fontes, 2011.

BAKHTIN, Mikhail. Glossário termos de Bakhtin. Palavras e Contrapalavras - Cadernos de Estudos I - Grupo de Estudos do Gênero do Discurso - GEGE, da Universidade Federal de São Carlos - UFSCAR. S o Carlos: Pedro\& João Editores, 2013. Disponível em: http://linguagenseminteracao.blogspot.com/2012/11/glossario-bakhtin.html. Acesso em: 9 ago. 2021.

BAKHTIN, Mikhail.; VOLOCHINOV, Valentin Nikoláievitch. Marxismo e filosofia da linguagem. 16. ed. São Paulo: Hucitec, 2014.

BAUMAN, Zygmund. Fronteiras do pensamento. 2011. (30m25s). Disponível em: https://www.youtube.com/watch?v=POZcBNo-D4A. Acesso em: 7 ago. 2021.

BURGE, Jess. Children of deaf adults: interpreting identity. Dissertação em Sociologia da Infância e dos Direitos da Criança. UCL Institute of Education. September 2018.

Disponível em:

https://www.academia.edu/37497366/Children_of_Deaf_Adults_Interpreting_Identity. Acesso em: 18 jul. 2021.

CAMPAROTO, Silvia Vitória. Maringá, 19 mar., 2018. Facebook: Silvia Vitória. Disponível em: https://www.facebook.com/profile.php?id=100003656084762. Acesso em: 11 ago. 2021.

FARACO, Carlos Alberto. Linguagem e diálogo: as ideias linguísticas do círculo de Bakhtin. São Paulo: Parábola, 2009.

LADD, Padd. Understanding Deaf Culture. Search of Deafhood. Londres: Channel View Publications. Edição do Kindle. 2003.

HALL, Stuard. A identidade cultural na pós-modernidade. Tradução Thomaz Tadeu da Silva, Guaracira Lopes Louro. 11. ed. 1. reimp. Rio de Janeiro: DP\&A, 2011.

HALL, Stuard. Quem precisa de identidade? In: SILVA, T. T. (Org.). Identidade e diferença: a perspectiva dos estudos culturais. 15. ed. Petrópolis: Vozes, 2014. p. 103133.

MARX, Karl.; ENGELS, Friedrich. A ideologia alemã. São Paulo: Centauro, 2004.

MORIÑA, Anabel. Investigar con historias de vida: metodogía biográfico-narrativa. Madrid: Narcea, 2017.

PRATT, Mary Louise. Arts of the contact zone. Academic Discourse: Readings for Argument and Analysis. Ed. Gall Stygall. Fort Worth: Harcourt College Publishers, 2000, p. 573-587.

PRESTON, Paul. Mother father deaf: living between sound and silence. EUA: Harvard, 1994. 
PRESTON, Paul. Prefácio. In: BISHOP, Michele; HICKS, Sherry. (Ed.). Hearing, mother father deaf: hearing people in deaf families. Washington, D.C.: Gallaudet University Press, 2008. (E-book).

QUADROS, Ronice Müller. Língua de herança. Porto Alegre: Penso, 2017.

QUADROS, Ronice Müller; MASSUTTI, Mara. Codas brasileiros: libras e português em zonas de contato. In: QUADROS, Ronice Müller; PERLIN, Gladis. (Org.). Estudos surdos II. Petrópolis: Arara Azul, 2007.

REGIS, Lourenço. Identidades consumidas. Revista Ambivalências, Sergipe, v. 3, n. 5, p. 290-295, 2015. Disponível em:

https://seer.ufs.br/index.php/Ambivalencias/article/view/3932/3295. Acesso em: 20 jul. 2021.

RODRIGUERO, Celma Regina Borghi; YAEGASHI, Solange Franci Raimundo. A família e o filho surdo: uma investigação acerca do desenvolvimento psicológico da criança segundo a abordagem histórico-cultural. 1. ed. Curitiba: CRV, 2013.

SANDER, Ricardo Ernani. Narrativas de Filhou Ouvintes de Pais Surdos - Codas, sobre o crescer bilíngue. 2020. 273 f. Tese (doutorado) - Universidade Estadual Paulista (Unesp), Faculdade de Filosofia e Ciências, Marília, SP, 2020. Disponível em: https://repositorio.unesp.br/handle/11449/202404 Acesso em: 24 de jul. 2021.

SILVA, Tadeu Tomaz (Org.). Identidade e diferença: a perspectiva dos estudos culturais. Rio de Janeiro: Petrópolis, 2014.

SKLIAR, Carlos (Org.). Educação e exclusão: abordagens sócio-antropológicas em educação especial. Porto Alegre: Mediação, 1997.

SKLIAR, Carlos (Org.). A surdez: um olhar sobre as diferenças. Porto Alegre: Mediação, 1998.

SOUZA, José Carlos Ferreira. Intérpretes Codas: construção de identidades. 2014. 148 f. Dissertação (Mestrado em Tradução) - Centro de Comunicação e Expressão, Universidade Federal de Santa Catarina, Florianópolis, 2014. Disponível em: https://repositorio.ufsc. br/bitstream/handle/123456789/136479/336246. pdf?sequence=1 . Acesso em: 24 jul. 2021.

VIGOTSKI, Lev Semionovitch. A construção do pensamento e da linguagem. São Paulo: Martins Fontes, 2001.

WOODWARD, Kathryn. Identidade e diferença: uma introdução conceitual. In: SILVA, Tomaz Tadeu da (Org.). Identidade e diferença: a perspectiva dos estudos culturais. 15. ed. Petrópolis: Vozes, 2000. 
http://dx.doi.org/10.5902/1984686X67637

\section{Notas}

${ }^{1}$ Children Of Deaf Adults - CODAS, usado na sociedade surda brasileira, assim como na maioria dos demais países.

2 SANDER, R.E. Narrativas de filhos ouvintes de pais surdos - Codas, sobre o crescer bilíngue. Tese de doutorado, 2002. Unesp. Disponível em: https://repositorio.unesp.br/handle/11449/202404.

${ }^{3}$ Adotaremos a expressão Círculo de Bakhtin para referir as obras de Bakhtin, mas que sobretudo envolviam sua autoria e de outros autores que integravam este círculo, dentre os quais destacam se Bakhtin, Volochínov, Medviédev, entre outros a partir das traduções que chegam no Brasil, no início dos anos 90 . Este Círculo foi formado por estudiosos, que tinham interesses filosóficos sobre os estudos da linguagem. Eles se encontravam para discutirem suas ideias, sobretudo entre os anos 1920 e 1930, na antiga Rússia.

${ }^{4}$ Autorizada pela comissão de ética da Plataforma Brasil n 2.670 .132 de 23 de maio de 2018, assinada pela coordenadora Cristiane Rodrigues Pedroni.

${ }^{5}$ Identidade/subjetividade usada dessa forma, sempre que necessário, por entender que um termo completa o outro, pois, ambas fazem parte da consciência humana e estão imbricadas, constituindo-se inseparavelmente.

${ }^{6}$ CAMPAROTO, Silvia Vitória de Souza. Maringá, 19 mar., 2018. Facebook: Silvia Vitória. Disponível em: https://www.facebook.com/profile.php?id=100003656084762. Acesso em: 11 nov. 2021.

${ }^{7}$ Neste estudo optamos por utilizar a palavra não-surdo em razão de fugir da regra, para os Codas. É o antônimo de surdos, dos pais surdos que usam a Libras, que são o primeiro modelo linguístico para os filhos ouvintes. 